\title{
Sic notus Ulixes?
}

Musa, dime del hábil varón que en su largo extravío, tras haber arrasado el alcázar sagrado de Troya, conoció las ciudades y el genio de innúmeras gentes. Muchos males pasó por las rutas marinas luchando por sí mismo y su vida y la vuelta al hogar de sus hombres, pero a estos no pudo salvarlos con todo su empeño que en las propias locuras hallaron su muerte. ¡Insensatos!

(Od. I, 1-7)

El viaje de Ulises es un regreso al hogar, un «nostos», castigo de los dioses por haber robado de Troya el Paladion (estatua de Palas-Atenea). El nostos debía ser interminable — diez años duró el de Ulises - o acabar trágicamente, como el de Agamenón. Más aun, Ulises, una vez de regreso, debía partir otra vez de viaje, según una profecía de Tiresias, como lo cuenta el mismo Ulises a su esposa:

No vinimos aún, ¡oh mujer!, al remate de todas nuestras penas, pues hay por delante labor sin medida, labor larga y difícil que habré de arrostrar por entero [...].

Me mandó recorrer los poblados de los hombres mortales llevando en las manos un remo.

(Od. XXIII, 249-268) 
Es decir, hasta encontrarse con un hombre que no conociera los remos. Llegado por fin a su casa,

[...] librado del mar, llegaríame la muerte, pero blanda y suave, acabada mi vida en la calma de lozana vejez.

(Od. XXIII, 281-283)

Sus hazañas guerreras se deben sobre todo a su astucia, a la traición y al espionaje; es responsable de la muerte del pequeño hijo de Héctor, Astiánax, y del sacrificio de Ifigenia y de Hécuba; redomado espía, suya fue la idea del caballo de Troya. En pocas palabras, Homero, aunque alaba su valentía, le atribuye casi siempre acciones poco honrosas. Ulises es el gran mentiroso de la epopeya. Ulises multiplica las narraciones falaces a Eumeo, a Antinoo, a Penélope e incluso, tan inútilmente, a su padre Laertes y a su protectora Atenea.

Ulises en la Odisea es un viajero, a pesar suyo, sin ninguna curiosidad por «conocer las ciudades y el genio de innúmeras gentes», contrariamente a lo que afirma Homero al inicio de la obra. Son excepcionales las ocasiones donde expresa un deseo de ver o de saber. Donde Polifemo «quise ver a aquel hombre» (Od. IX, 229). Ante las Sirenas, «en mi pecho yo anhelaba escucharlas» (Od. XII, 192-193). Durante la deleitosa permanencia donde Circe, son sus compañeros quienes le hacen recordar su patria: «Hora es ya, buen señor, de que vuelvas la mente a tu patria» (Od. X, 472). Las innúmeras gentes se reducen solo al idealizado pueblo de los feacios, adonde llega, por otra parte, por un naufragio.

Varios autores de la Antigüedad se han burlado de la personalidad de Ulises. Leamos, por ejemplo, la introducción de la Historia verdadera de Luciano. Los romanos, menos Virgilio, tendieron a magnificar el nombre de Ulises. Cicerón (De fin. V, XVIII, 48 ss.) cuenta que el canto de las Sirenas prometía la ciencia, "una cosa que no es maravilla que un hombre ambicioso de sabiduría prefiera a su patria». Para Séneca (De const. sap. II, 2), «nuestros estoicos proclamaron a Ulises y Hércules sabios, invencibles en los trabajos, menospreciadores del placer, vencedores de todos los miedos». Horacio se entusiasma más por Ulises: 
Homero nos propuso un ejemplar útil del poder de la virtud y de la sabiduría: es Ulises, que, domador de Troya, estudió con inteligencia las ciudades y las costumbres de muchos pueblos, y que, mientras efectuaba su regreso y el de sus compañeros, soportó en el vasto mar muchas crueles desgracias sin ser sumergido por las olas de la adversidad. Conoce los cantos de las Sirenas y las bebidas de Circe: si las hubiera tomado con la estúpida avidez de sus compañeros, habría sido un vil esclavo de una impúdica prostituta o convertido en un perro inmundo o en un cerdo amante del fango. (Ep. I, II, 17-26)

Virgilio, en cambio, no escatima los insultos contra Ulises: durus, pellax, saeuus, scelerum inuentor, hortator scelerum, dirus, fandi fictor... Al pasar por Ítaca los troyanos maldicen la tierra que nutrió al cruel Ulises. En los Infiernos, Deífobo lo llama Aeolides, el eolio, porque Anticlea, madre de Ulises, había sido violada por Sísifo, hijo de Éolo. En los Infiernos también, Ulises, junto con los jefes de los dánaos y las falanges de Agamenón, huye cobardemente ante la sola presencia de Eneas (En. VI, 489-493).

Diomedes, compañero inseparable de Ulises y ya instalado en Argiripa, es solicitado vanamente por Turno para una alianza en contra de los troyanos, y confiesa la superioridad de Eneas: «Creedme, por propia experiencia sé cuán grande es cuando surge con su espada, qué rayo es cuando blande su lanza» (En. XI, 283-284).

Con la invasión de los bárbaros se perdieron en la Europa occidental todos los manuscritos de las obras homéricas y, lo que es peor, se perdió el conocimiento del griego. Se escribieron, empero, varias refundiciones, más o menos fantasistas, de la Ilíada que sirvieron en la Edad Media para recordar la guerra de Troya. Dictis el Cretense escribió una obra que fue traducida por Lucio Septimio bajo el título de Ephemeris belli Troiani. Dares el Frigio publicó una Historia de excidio Troiae. En el s. XIII, Benoît de Sainte-Maure escribió el Roman de Troie que fue traducido o más bien adaptado por Guido delle Colonne con el título de Historia destructionis Troiae.

Es más que probable que Dante desconoció estas refundiciones. Las únicas noticias, pues, que le llegaron sobre Ulises fueron de los romanos, Virgilio a la cabeza con su Eneida. Pero el genio de Dante logró fabricar con Ulises una de las páginas más importantes de la 
literatura universal: cincuenta y dos versos que han hecho y hacen emocionar a sus lectores de todo el mundo durante más de siete siglos. Pero hasta ahora subsiste la duda de si leemos como se debe estos magníficos versos. ¿Conocemos al Ulises dantiano? Sic notus Ulixes?, como nos gritaría Laoconte.

Ulises aparece en el canto XXVI del Inferno de la Comedia. Estamos en la «bolsa» octava de los consejeros de fraude del gran círculo octavo de los fraudulentos. Cada condenado está encerrado dentro de una llama semoviente por la «bolsa». La originalidad del castigo de Ulises consiste en estar encerrado en la llama junto con Diomedes, su compañero de fechorías. Por encima de ellos, la llama se bifurca como la lengua de una serpiente. Dante manifiesta a su guía Virgilio el deseo de hablar con ellos, pero este le advierte que no conviene que sea él quien los interrogue porque, siendo griegos, quizá no se dignen responderle. La llama más alta, la de Ulises, se apresta a hablarles:

\section{Quando}

mi diparti' da Circe, che sottrasse

me più d'un anno là presso a Gaeta,

prima che sì Enea la nomasse,

né dolcezza di figlio, né la pièta

del vecchio padre, né ' 1 debito amore

lo qual dovea Penelopè far lieta,

vincer poter dentro da me l'ardore

ch'i' ebbi a divenir del mondo esperto,

e delli vizi umani e del valore;

ma misi me per l'alto mare aperto

sol con un legno e con quella compagna

picciola dalla qual non fui diserto.

L'un lito e l'altro vidi infin la Spagna,

fin nel Morrocco, e l'isola de' Sardi,

e l'altre che quel mare intorno bagna.

Io e' compagni eravam vecchi e tardi

quando venimmo a quella foce stretta

dov'Ercule segnò li suoi riguardi

acciò che l'uom più oltre non si metta: 
dalla man destra mi lasciai Sibilia,

dall'altra già m’avea lasciata Setta.

"O frati", dissi, "che per cento milia

perigli siete giunti all'occidente,

a questa tanto picciola vigilia

de' nostri sensi ch'è del rimanente,

non vogliate negar l'esperïenza,

di retro al sol, del mondo sanza gente.

Considerate la vostra semenza:

fatti non foste a viver come bruti,

ma per seguir virtute e canoscenza”.

Li miei compagni fec'io sì aguti,

con questa orazion picciola, al cammino,

che a pena poscia li avrei ritenuti;

e volta nostra poppa nel mattino,

dei remi facemmo ali al folle volo,

sempre acquistando dal lato mancino.

Tutte le stelle già dell'altro polo

vedea la notte, e 'l nostro tanto basso,

che non surgea fuor del marin suolo.

Cinque volte racceso e tante casso

lo lume era di sotto dalla luna,

poi che 'ntrati eravam nell'alto passo,

quando n'apparve una montagna, bruna

per la distanza, e parvemi alta tanto

quanto veduta non avea alcuna.

Noi ci allegrammo, e tosto tornò in pianto

ché della nova terra un turbo nacque,

e percose del legno il primo canto.

Tre volte il fé girar con tutte l'acque:

alla quarta levar la poppa in suso

e la prora ire in giù, com'altrui piacque,

infine che 'l mar fu sopra noi richiuso.

(Comedia, Inf. XXVI, 90-142) 
[Cuando

finalmente dejé a Circe, que me había secuestrado por más de un año allí, cerca de Gaeta antes de que así Eneas la llamara,

ni el cariño de un hijo, ni la piedad filial hacia mi viejo padre, ni el amor debido a Penélope que debía hacerla feliz

pudieron vencer en mí el ardor que tenía de conocer el mundo, los vicios y el valor de los hombres;

me arrojé, pues, a la alta mar abierta

solo con una nave y con aquella pequeńa compañía que nunca me abandonó.

Una y otra orilla por fin vi de España y de Marruecos, y la isla de los sardos y las otras que ese mar en torno baña.

Yo y mis compañeros éramos viejos y tardos cuando llegamos a aquel estrecho donde Hércules había levantado los resguardos para que el hombre no avanzara más allá:

a la derecha dejé Sevilla, y al otro lado Ceuta ya me había dejado.

“¡Oh hermanos!- dije- que por cien mil peligros habéis llegado al occidente en esta nuestra breve vigilia de los sentidos que nos queda, no os neguéis a la experiencia, siguiendo al sol, del mundo deshabitado.

Considerad vuestro origen: no habéis sido hechos para vivir como animales, sino para señalaros en valor y conocimiento".

Estimulé tanto a viajar a mis compañeros con esta breve exhortación que a duras penas luego los habría retenido; vuelta nuestra popa a la alborada, de los remos hicimos alas al loco vuelo, 
avanzando siempre por la izquierda.

Todas las estrellas del otro polo

la noche ya veía, y al nuestro tan bajo

que no surgía de la superficie marina.

Cinco veces encendida y otras tantas apagada era

la luz de la luna encima de nosotros

desde que entramos en la ardua empresa,

cuando apareció ante nosotros una montańa, bruna

por la distancia, y me pareció tan alta

que no me acuerdo haber visto jamás otra parecida.

Nos alegramos, mas pronto la alegría se tornó en llanto:

porque de la nueva tierra nació un remolino

y golpeó la proa del navío.

Tres veces la hizo girar con todas sus aguas:

a la cuarta vuelta levantó la popa arriba

mientras la proa se hundía, como gustó a Otro,

hasta que el mar se cerró sobre nosotros.]

Dante requiere varias lecturas. En la primera el lector debe aplicar sus sentidos para apreciar la versificación, los encabalgamientos, las figuras retóricas: aliteraciones, metáforas, alusiones, el verdadero sentido de las palabras y las reminiscencias clásicas a fin de hacer sobresalir la originalidad de Dante. En este pasaje lo primero que notamos es la elevación de estilo, propio de la épica. El uso de la primera persona plural le da un tinte más solemne y patético. Sin embargo, muy pronto (Inf. XXVII, 21) nos enteramos de que Virgilio se despide de Ulises con una chocante despectiva frase dialectal: Istra ten va, più non t'adizzo [Ahora vete de aquí, ya no te estimulo a hablar].

Hay dos pasajes en la Comedia que aluden a este episodio. Tras pocos capítulos el lector advierte que la altísima montaña a la que Ulises quería llegar era la del Purgatorio. En Pg. I, 130-132 Dante nos cuenta:

Venimmo poi in sul lito diserto,

che mai non vide navicar sue acque

omo che di tornar sia poscia esperto. 
[Llegamos luego a la solitaria orilla,

que nunca vio sus aguas ser navegadas

por alguien que luego conociera el retorno.]

Más tarde, desde el octavo cielo, el estelífero, Beatriz, la nueva guía de Dante, le sugiere mirar hacia la tierra. Al divisar el Atlántico, contempla desde el espacio il varco folle d'Ulisse [la loca ruta de Ulises]. El lector ya debe estarse preguntando: ¿por qué loco? ¿Por abandonar a su hijo, a su padre y a su mujer? ¿Por la avanzada edad de los navegantes? ¿Por su objetivo — conocer el mundo, los vicios y el valor de los hombres, que contradice la ruta tomada - por el mundo deshabitado? ¿Por ir más allá de las columnas de Hércules?

No nos queda otro camino que recurrir a la alegoría, figura predilecta de Dante para enseñar la doctrina. Es decir, trascender el plano literal (o plano de juego) para llegar al plano serio, que, en este caso, es muy fácil de alcanzar. Lo que Ulises buscó con su viaje fue arribar a la montaña del Purgatorio, es decir, a la salvación, con su propio esfuerzo y con sus propios medios. No tomó en cuenta que la salvación es más cuestión de gracia divina que de esfuerzo humano. El alma se salva per sola grazia, non per esser degna (Pd. XII, 42): únicamente por gracia de Dios, no por ser digna. El cristiano que piensa al revés cae inevitablemente en el pelagianismo, herejía ya combatida con brío por san Agustín.

Los románticos cayeron en «locas» interpretaciones por olvidarse de que la Comedia, mal que les pese es una obra esencialmente religiosa. Celebraron en Ulises la osadía sin frenos de la razón y exaltaron las empresas insensatas e imposibles. Ulises se convirtió en otro Galileo, mártir del afán de conocer, de una titánica-romántica voluntad de rebelión. Para Benedetto Croce —quizá el peor intérprete de Dante— se trata de «un sublime pecado». Leo en un libro alemán reciente las siguientes sandeces: «Dante ha hecho del Ulises de la Edad Media, vale decir, de la tardía Antigüedad, un auténtico representante del Renacimiento, una figura que por la audaz concepción y la representación trágicamente grandiosa puede ser comparada a las mayores figuras de la humanidad del Renacimiento, a César Borgia como a Colón, al príncipe de Maquiavelo como al shakespeareano Ricardo III y al Doctor Fausto del drama de Marlowe».

Y es que el genio de Dante ha convertido a varios condenados en perfectos seductores. Releamos el bello canto de Francesca y Paolo. Si no realizamos aquí la segunda lectura que 
recomendamos, Francesca y Paolo, vulgares adúlteros, se convertirán en inocentes víctimas del «amor», que justifica todo en esta época descristianizada.

En resumen, Ulises es la alegoría del pelagianismo, herejía que todavía repta en la mentalidad de muchos cristianos. 